\title{
Electric Vehicle Charging Management Algorithm for a UK Low-Voltage Residential Distribution Network
}

\author{
Zhi Qiao \\ School of Engineering and Applied Science \\ Aston University \\ Birmingham, United Kingdom \\ qiaoz@aston.ac.uk
}

\author{
Jin Yang \\ School of Engineering and Applied Science \\ Aston University \\ Birmingham, United Kingdom \\ j.yang8@aston.ac.uk
}

\begin{abstract}
The integration of Electric Vehicles (EVs) into lowvoltage (LV) residential distribution networks inevitably increases the overall demand, especially peak demand, which may cause thermal or voltage issues. In this paper, a $400 \mathrm{~V}$ practical residential distribution network is modelled and used to quantify these impacts due to the growing penetration of EVs. Residential load profiles in 1-minute resolution and $\mathrm{EV}$ charging profiles with recorded State of Charge (SOC) are randomly and statistically created. Then, a simple charging management algorithm with locally made decision is suggested at EV users' charging points. Results prove that this approach can mitigate the negative impacts of EV charging on network assets. Moreover, it can reduce EV users' electricity cost for charging based on existing UK electricity price scheme 'Economy 7,' without compromising EV usage or substantial network infrastructure reinforcement or installation of extensive monitor, control and communication system. The simulation models and analysis are implemented in MATLAB/OpenDSS as an LV distribution network simulation platform.
\end{abstract}

Index Terms-Low-voltage distribution networks, electric vehicles, charging management, multi-objective optimization, high resolution load profile

\section{INTRODUCTION}

A series of low carbon policies are deployed by the UK government to reflect the growing concerns of greenhouse effect, fossil fuel shortage, energy security etc., known as "low carbon" strategies. Strategic incentives, for example, on plugged-in electric vehicles (EVs) are offered by the government to encourage domestic customers to participate [1].. EVs are advantageous for their low carbon dioxide emission and relative low cost compared with traditional combustion engine vehicles. It is predictable that there are growing penetration of EVs integrated into LV distribution networks. Conventional $400 \mathrm{~V}$ distribution networks are designed and rated base on After Diversity Maximum Demands (ADMD), number of houses and certain formula depends on the size and type of network. For example, for electric central heating dwelling, ADMD is $3 \mathrm{~kW}$.For the distribution network with 292 customers used in this paper, a $500 \mathrm{kVA}$ transformer is selected for this area. A Nissan LEAF vehicle charges at $3.6 \mathrm{~kW}$ when plugged-in to the mains (slow charging mode) or at $6.6 \mathrm{~kW}$ when charging via home charging unit (fast charging mode) [2]. Hence even in slow charging mode, the charging power is higher than the ADMD for a house. Therefore EVs as extra loading to the network can cause thermal or voltage issues, particularly when the penetration of EVs is considerable.

Published work [3-5] reported that the growing penetration of EVs can cause thermal, voltage or power loss issues for existing distribution networks. Various potential solutions are suggested in literature [4, 6-9], including EV charging management $[4,7,9]$, vehicle back-feeding electricity to the grid, or known as V2G [6]. Real-time online management [4]can mitigate these issues. However, these algorithms demand large-scale measurement, build-in communication framework and central control unit. Along with asset reinforcement, the capital and maintenance costs can be enormous. Without proper operational control, network reliability can be reduced which means EV customers' requests are compromised.

This paper proposes a simple EV charging management algorithm based on locally controlled (decentralized control of) charging points, aiming to mitigate the impacts on LV distribution network and reduce EV charging costs, without harming user's usage experience or increasing EV charging connection times, which may reduce battery life time. A practical UK LV residential distribution networks located in Midlands of England with 292 domestic customers is used to quantify the impact of $\mathrm{EV}$ charging. 1-minute resolution residential profiles and EV charging profiles with recorded State of Charge (SOC) are created randomly and statistically for simulation. Optimal charging threshold and start charging time is tested to guarantee network performance and EV users' experience. Optimization result is compared with a published novel real-time charging dispatch algorithm relying on extensive communication infrastructure with a control center implemented to a similar network. Proposed approach is adopted to another LV distribution network which has similar configuration and load characteristics for further validation. 
This paper is organized as follows. Section II describes the simulation platform and all the input data including LV networks, residential artificial load profiles and EV charging profiles at both slow and fast charging modes. In Section III, the impact of EV charging on network is quantified at increasing penetration. In Section IV, a simple EV charging management algorithm based on local control of the charging point is proposed for EV charging optimization. This optimization result and discussions about this method and its application is presented in in Section V. Conclusions and further works are drawn in Section VI.

\section{NETWORK MODELLING AND DATA}

A very detailed LV distribution network models with service cables up to the customers' cut-out is introduced in this section. 1-minute resolution load profiles is created using a model presented in [10]. In [11], charging behavior of 78 Nissan LEAF vehicles is statistically analyzed. EV charging profiles are generated using this model then converted into 1minute resolution. This network and profiles together will be a good benchmark testbed for LV distribution systems with integrated large-scale renewable energy resources (RESs) under the Smart Grid scenario.

\section{A. Network Simulation Platform}

Various formats of input data and interface requirement of load flow program means that a platform is required. Considering the purpose of optimization, MATLAB is used as the main driving engine. Load profiles and EV charging profiles are generated by MATLAB by calling either the CREST tool or codes based on the model aforementioned. Load flow analysis function is conducted by Open Distribution System Simulator (OpenDSS), which is an open source software for electric distribution systems simulation [12]. Fig.1 shows an overall structure of the proposed simulation platform.

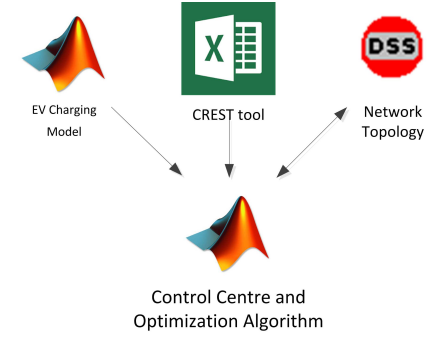

Fig. 1. The structure of the proposed simulation platform

\section{B. Network Description and Models}

A real LV residential distribution networks located in Midlands of England is used as a case study. The LV network with 292 domestic customers is supplied by a $500 \mathrm{kVA}$ distribution transformer. Fig. 2 shows the geographical diagram of the network.

\section{Domestic Load Profiles}

Validated load profile is essential in power system study. LV network customers' load profiles are conventionally not monitored. Even if these are available with rolling-out smart meters, data from customers can be sensitive or even confidential. To better understand the electricity consumption behavior and the accumulated network dynamic loading, it is necessary to study domestic loads from different point of view. In [13], major household appliances and their power ratings are selected for load profile study in 1-second resolution. Customer load profiles are also modelled according to survey data, including the number of active people in a house, the behavior of household appliance usage [10]. All domestic customers are modelled as non-electric central heating residential loads (i.e. gas heating available in the dwelling). 292 independent load profiles on a weekday in February 2015 are generated by using the high resolution model [10] driven by MATLAB codes. 10-minute average accumulated profiles are compared with measured data at substation, whose resolution is 10-minutes for validation, shown in Fig. 3. This figure shows that the accumulated artificial load profile has high similarity with the data measured at substation hence customer load profiles are validated.

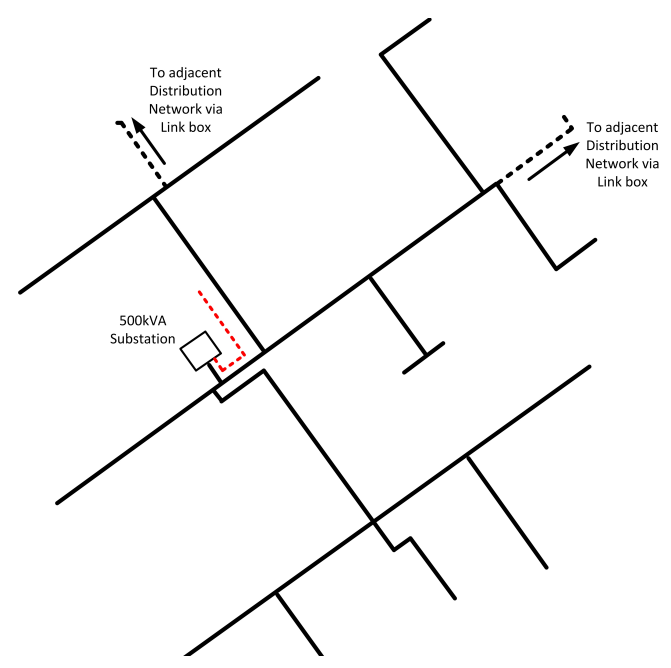

Fig. 2. Geographical diagram of the object LV distribution network.

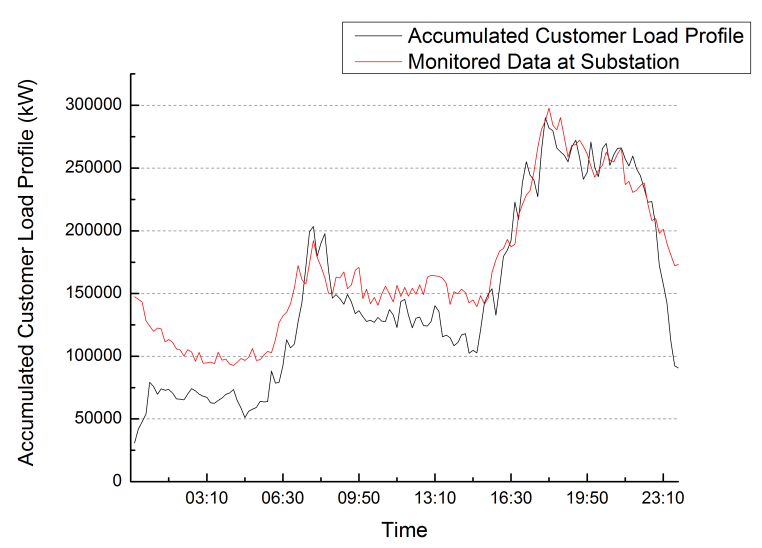

Fig. 3. Accumulated artificial load profile compared with measured data at substation. 


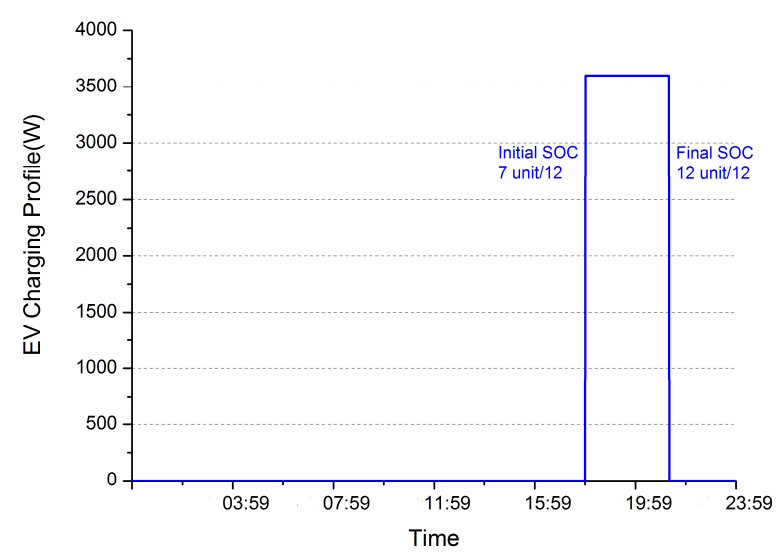

Fig. 4. Example of EV charging profile with once connection in a day.

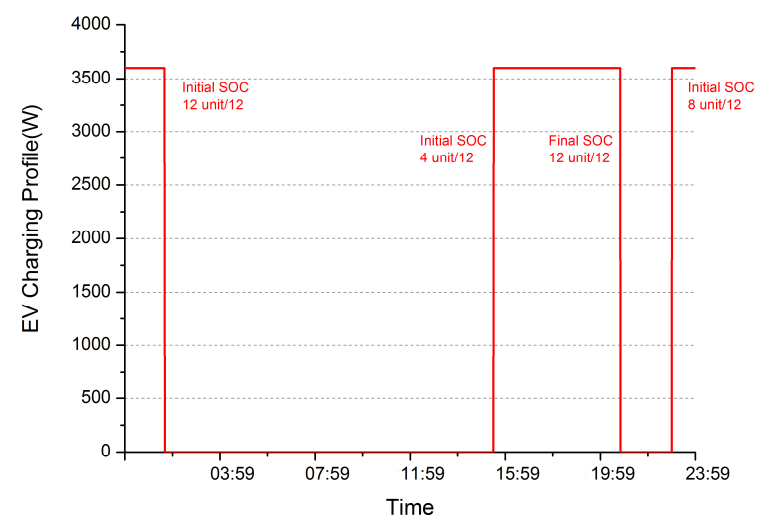

Fig. 5. Example of EV charging profile with twice connections in a day.

\section{EV Charging Profiles}

To quantify the impact of EV charging on distribution networks, validated time series EV charging profiles are required. Statistical analysis of EV charging behavior in the UK is presented in [11], after monitoring more than 200 Nissan LEAF vehicles' charging, with various start charging time, initial SOC and final SOC, for over one year. A probability distribution function (PDF) presents the relationship among number of connections each day, start charging time of each connection, initial and final state-ofcharge (SOC) of the battery. LEAF uses $24 \mathrm{kWh}$ battery charging at $3.6 \mathrm{~kW}$ when it connected to the mains or at $6.6 \mathrm{~kW}$ when charging via installed charging unit in the dwelling. These home charging unit can be controlled by smartphone or users' pre-set program which can make the EV charging flexible to take advantage of Economy 7 tariff, i.e. to charge EVs during the night to take advantage of the off-peak electricity price, which can be up to half of the electricity price during the day. A set of charging profiles of 292 independent profile are created according to this PDF model. Statistical analysis of this set of data proves the characteristic is in line with the model [11]. Two examples of EV charging profiles are plotted in Figs.4 and 5. Initial SOC and final SOC of each charging period are annotated.
All 292 independent charging profiles are summed and plotted in Fig. 6. Compared with the original customer load profile shown in Fig. 3, both graphs show peak at around 5pm to $10 \mathrm{pm}$. The superposition of this peak will burden the substation and go beyond its thermal limit once the penetration is high. In the next section, this will be quantified.

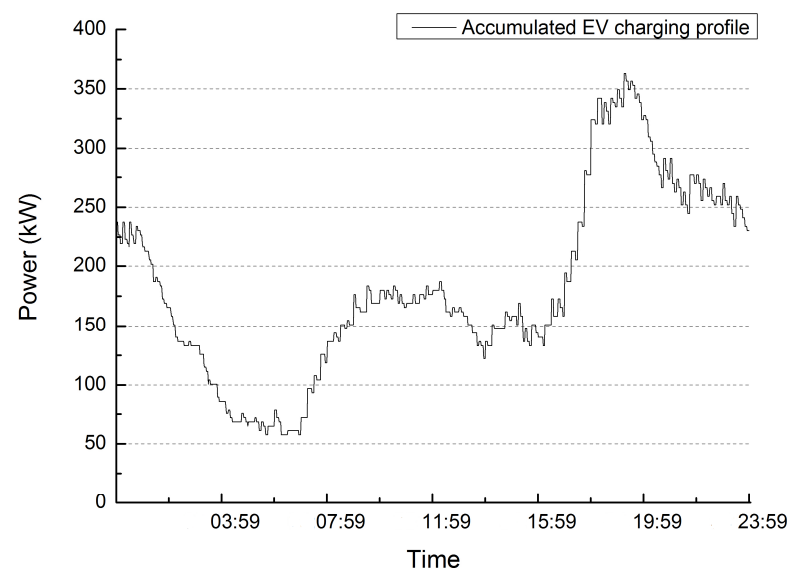

Fig. 6. Accumulated EVcharging profile.

\section{EV CHARGING IMPACT RESULTS}

\section{A. Thermal Issue}

$\mathrm{EV}$ allocation indicator is used to describe penetration of EVs and also employed to randomly allocate these EVs geographically. Time series simulation results obtained from the platform indicate that when $50 \%$ number of the houses own one EV, the network can still support these loads although it operates near the thermal limit during peak loads. Thermal issue occurs to the substation transformer when the EV penetration goes over 50\%, as shown in Fig.7.

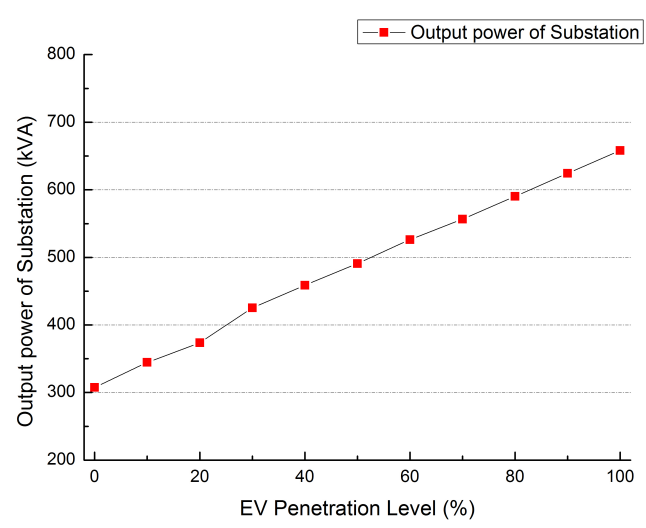

Fig. 7. Power at substation with increasing penetration of EVs.

\section{B. Voltage Issue}

Voltage issue only occurs at the most remote customer from the substation. Still the lowest value simulated is above 0.93p.u. for a very short period of time. Therefore, voltage regulation is not a concern for this case study. However, for 
fast charging mode, it is possible to breach the voltage limit as the power increase is significant. This result also shows that the current planning practices of LV distribution network consider good safety margin. A strong and robust LV distribution network has a higher chance to integrate more renewable energy resources.

\section{EV CAHRGING MANAGEMENT AlgRITHM}

As reviewed in Section I, intelligent EV charging management systems normally require extensive communication which means high capital investment and later on maintenance expenses. Therefore a simple EV charging management algorithm considering local charging point and Economy 7 tariffs is introduced in this section to reduce the above thermal issues.

The aims of this optimization include: (a) mitigate negative thermal impact; (b) reduce customer EV running cost via shifting EV charging to low tariff period, i.e. during the night; (c) keep the existing connection time to ensure the life of battery. Therefore this is a multi-objective optimization problem to benefit both EV users and DNOs (distribution network operators).

The average trip distance by a private car is 8.4 miles according to data from a report of statistical trends on the British transport sector [14]. Nissan LEAF can travel up to 124 miles with $24 \mathrm{kWh}$ battery capacity, which consists of 12 battery unit with $2 \mathrm{kWh}$ capacity each, i.e. for each single charged unit, the capacity can keep the running for about 12 miles. A threshold value is set to 3 -unit which can provide sufficient electricity to the vehicle for a short journey, of about 36 miles. If the vehicle is connected to the mains for charging with SOC less than 3-unit of the battery out of the total 12, the algorithm will interrupt this charging. This threshold can guarantee the EV user a basic request for any unexpected trip.

The logic of this algorithm is that if any vehicle connected to the mains with SOC higher than 3-unit, the charging will be postponed to the night when the household load is low and electricity price is relevant low as well. The lower SOC will get priority to start charging. Two examples are show in Figs. 8 and 9 to illustrate this process.

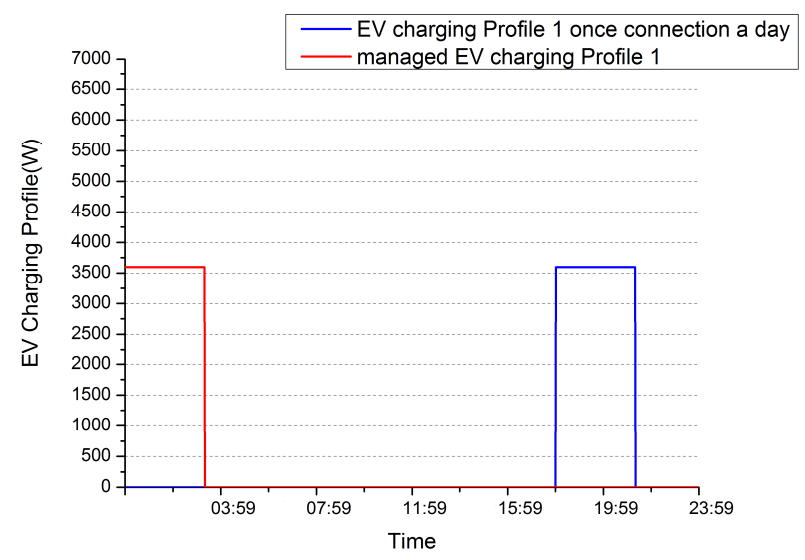

Fig. 8. Example of a charging management, once connection a day.

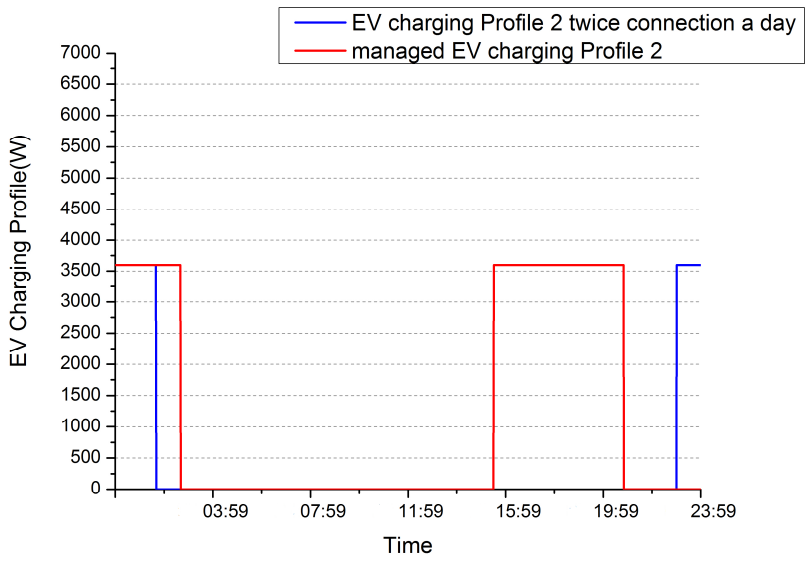

Fig. 9. Example of a charging management, twice connection a day

Various combinations of charging threshold and start charging time are tested to reduce overall load peak of the system and customer costs under Economy 7 tariffs. Any charging with initial SOC higher than 10 out of 12 will be postpone to $3 \mathrm{am}$ in the morning; if the initial SOC is 8 or 9 , $\mathrm{EV}$ will be charged after 2am; if the initial SOC is 7, EV will start charging at $12 \mathrm{am}$; if initial SOC is between 4 to 6 , charging starts from $10 \mathrm{pm}$.

According to the algorithm described previously, the overall EV charging profile can be modified into the curve shown in Fig. 10. It can be seen that the peak of the accumulated EV charging profile has been moved from around $8 \mathrm{pm}$ to after $12 \mathrm{am}$ next day. Therefore considering the accumulated load profile (in Fig. 3) where the peak is between $7 \mathrm{pm}$ and $11 \mathrm{pm}$, the total demand peak is effectively shifted and reduced.

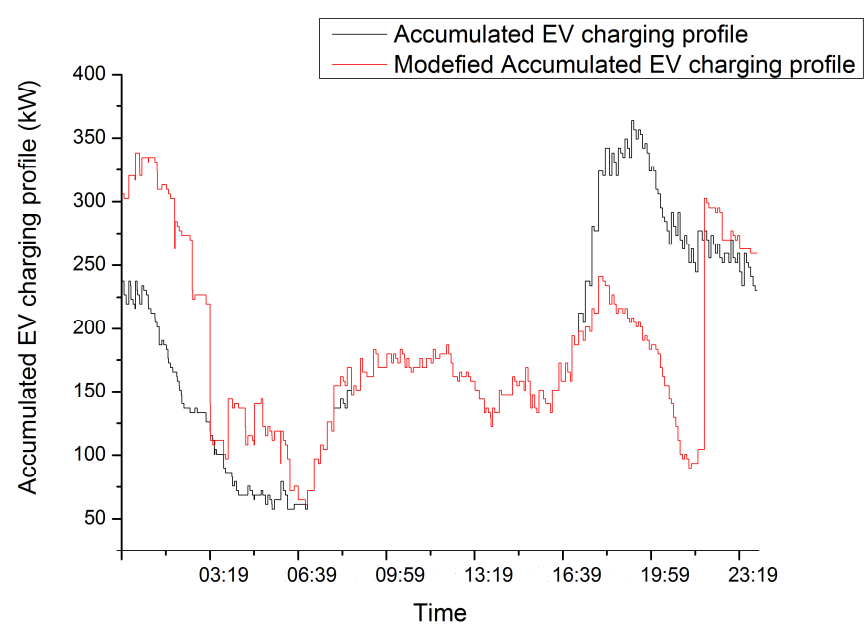

Fig. 10. EV charging profile after local charging management. 


\section{COMPARISON AND DISCUSSIONS}

The same EV allocation indicator addressed in section II and household load profiles are used for load flow analysis of the whole network with modified EV charging profiles. Thermal issue occurs to substation (500kVA) when the EV penetration is above 70\%, as shown in Fig.11. Compared with results in Fig. 7, this optimization avoids the network EV capacity by $20 \%$ before the substation transformer reaches its thermal limit of 500kVA for this network.

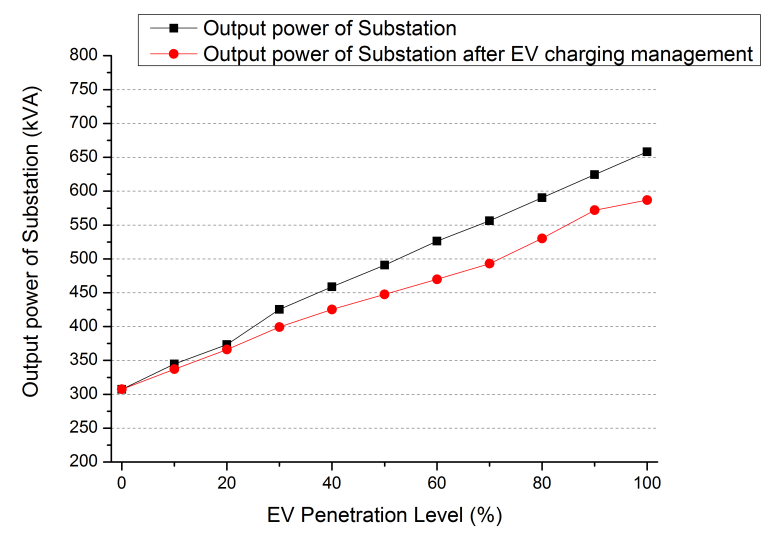

Fig. 11. Result comparison with/without EV charging management.

TABLE I. TARIFF OF ECONOMY 7 VS NORMAL ELECTRICITY-ONLY

\begin{tabular}{|l|l|l|l|}
\hline Tariff & PEAK RATE & $\begin{array}{l}\text { OFF-PEAK } \\
\text { RATE }\end{array}$ & $\begin{array}{l}\text { STANDING } \\
\text { CHARGE }\end{array}$ \\
\hline $\begin{array}{l}\text { Normal } \\
\text { electricity-only }\end{array}$ & $£ 9.4 \mathrm{p} / \mathrm{kWh}$ & $£ 9.4 \mathrm{p} / \mathrm{kWh}$ & $£ 19.8 \mathrm{p} /$ day \\
\hline Economy 7 & $£ 12 \mathrm{p} / \mathrm{kWh}$ & $£ 6.3 \mathrm{p} / \mathrm{kWh}$ & $£ 13.6 \mathrm{p} /$ day \\
\hline
\end{tabular}

$\mathrm{p}-$ British pence

Meanwhile, according to the Economy 7 tariffs, off-peak times are usually between $1 \mathrm{am}-8 \mathrm{am}$ during winter. Electricity price per unit $(\mathrm{kWh})$ is compared in Table I [15]. The average charging cost for each house is calculated by the accumulated charging profile power values multiply the corresponding tariff during that time. From calculation, with the proposed charging management, the average charging cost is effectively reduced: from $£ 1.66$ per day each $\mathrm{EV}$ before smart charging management to $£ 1.57$ per day each $\mathrm{EV}$ after implementing this algorithm with Economy 7 tariffs. This reduction, to some extent is limited, however, considering the $20 \%$ improvement to network capacity and customers EV usage, it is advantageous in achieving a balance amongst all objectives. It is worth mentioning that if charging cost is the most important factor to consider, the charging management can be flexible to reflect that by shifting the EV charging profile further to e.g. after $1 \mathrm{am}$ but before $6 \mathrm{am}$. In this way, not only the charging cost can be reduced further, but also the EV usage on the day would not be affected.

\section{CONCLUSION}

This paper presents a detailed LV distribution system simulation platform, based on which the impact of EV charging on thermal and voltage issues are quantified. For an
LV practical residential distribution network with high penetration of EVs, this multi-objective optimization problem to consider all factors is challenging. To achieve this aim, an EV charging management algorithm is proposed considering EV usage, battery life (EV connection times), distribution network capacity and electricity tariffs. Result shows both DNOs and customers can benefit from this algorithm. The network reinforcement for EV integration can be postponed as network capacity increased by $20 \%$ in this case study. In terms of average EV users' charging expense, the reduction is limited due to that the algorithm put the security of network operation and EV usage in advantage to the charging cost. This can be improved by further tariff analysis.

\section{ACKNOWLEDGMENT}

The authors wish to thank Western Power Distribution plc.for their support to realize the production of this paper.

\section{REFERENCES}

https://www.gov.uk/plug-in-car-van-grants/further-information https://www.nissan.co.uk/

M. Kazerooni and N. C. Kar, "Impact analysis of EV battery charging on the power system distribution transformers," in Electric Vehicle Conference (IEVC), 2012 IEEE International, 2012, pp. 1-6.

J. Quiros-Tortos, L. F. Ochoa, S. W. Alnaser, and T. Butler, "Control of EV Charging Points for Thermal and Voltage Management of LV Networks," IEEE Transactions on Power Systems, vol. PP, pp. 1-12, 2015.

R. Scharrenberg, B. Vonk, and P. H. Nguyen, "EV stochastic modelling and its impacts on the Dutch distribution network," in Probabilistic Methods Applied to Power Systems (PMAPS), 2014 International Conference on, 2014, pp. 1-6.

Y. Ma, T. Houghton, A. Cruden, and D. Infield, "Modeling the Benefits of Vehicle-to-Grid Technology to a Power System," IEEE Transactions on Power Systems, vol. 27, pp. 1012-1020, 2012.

L. M. O. Queiroz and C. Lyra, "Adaptive Hybrid Genetic Algorithm for Technical Loss Reduction in Distribution Networks Under Variable Demands," IEEE Transactions on Power Systems, vol. 24, pp. 445-453, 2009.

H. Rahimi-Eichi, U. Ojha, F. Baronti, and M. Y. Chow, "Battery Management System: An Overview of Its Application in the Smart Grid and Electric Vehicles," IEEE Industrial Electronics Magazine, vol. 7, pp. 4-16, 2013.

K. L, E. Saarijrvi, M. Lehtonen, A. Rosin, and M. H, "Load shifting in the existing distribution network and perspectives for EV charging-case study," in IEEE PES Innovative Smart Grid Technologies, Europe, 2014, pp. 1-6.

I. Richardson, M. Thomson, D. Infield, and C. Clifford, "Domestic electricity use: A high-resolution energy demand model," Energy and Buildings, vol. 42, pp. 1878-1887, 2010.

J. Quir, T. s, L. F. Ochoa, and B. Lees, "A statistical analysis of EV charging behavior in the UK," in Innovative Smart Grid Technologies Latin America (ISGT LATAM), 2015 IEEE PES, 2015, pp. 445-449.

D. Montenegro, M. Hernandez, and G. A. Ramos, "Real time OpenDSS framework for distribution systems simulation and analysis," in Transmission and Distribution: Latin America Conference and Exposition (T\&D-LA), 2012 Sixth IEEE/PES, 2012, pp. 1-5.

M. Pipattanasomporn, M. Kuzlu, S. Rahman, and Y. Teklu, "Load Profiles of Selected Major Household Appliances and Their Demand Response Opportunities," IEEE Transactions on Smart Grid, vol. 5, pp. 742-750, 2014.

http://www.dft.gov.uk/pgr/statistics/datatablespublications/tsgb/ http://www.moneysavingexpert.com/utilities/economy-7 